\title{
Spatial mismatch for distinct socioeconomic groups in Xiamen, China
}

\author{
Yongling Li \\ Institute of Geographic \\ Sciences and Natural Re- \\ sources Research, Chinese \\ Academy of Sciences, and \\ Utrecht University \\ Y.li2@uu.nl
}

\section{Pieter Hooimeijer \\ Utrecht University \\ P.Hooimeijer@uu.nl}

\author{
Stan Geertman \\ Utrecht University \\ S.C.M.Geertman@uu.nl \\ Wangtu (Ato) Xu \\ Xiamen University \\ ato1981@xmu.edu.cn
}

\author{
Yanliu Lin \\ Utrecht University \\ yanliu_lin@hotmail.com \\ Jie Huang (corresponding \\ author) \\ Institute of Geographic \\ Sciences and Natural Re- \\ sources Research, Chinese \\ Academy of Sciences \\ huangjie@igsnrr.ac.cn
}

\begin{abstract}
Studies have found that spatial mismatch is a universal phenomenon, although both their substantive and methodological focus can differ substantially. In China, there is a growing body of literature on spatial mismatch, but few studies have measured the degree of spatial mismatch between local and migrant workers in different occupations. To fill this gap, this research investigates the spatial mismatch for different socioeconomic groups in Xiamen according to their "hukou" status and occupation. As one of the country's first four special economic zones, Xiamen achieved housing marketization earlier than most other Chinese cities, attracting a large amount of capital and migrants, and shaping different spatial patterns of local workers and migrant workers. The findings show that blue-collar, pink-collar, and white-collar workers, who are further categorized as either locals or migrants, experience varying degrees of job accessibility and spatial mismatch. In addition, even though migrant workers experience less spatial mismatch, they still have disadvantages in terms of commuting time due to their travel mode. The results presented in this paper are helpful for understanding the spatial mismatch for various social groups and facilitating sustainable mobility and social equity.
\end{abstract}

Keywords: Spatial mismatch, job accessibility, blue-collar, pink-collar, white-collar, local and migrant workers, Xiamen

\section{Article history:}

Received: August 27, 2020

Received in revised form:

October 25, 2021

Accepted: November 10, 2021

Available online: January 24,

2022

\section{$1 \quad$ Introduction}

A number of studies on spatial mismatch have been published since Kain (1968) investigated how the spatial mismatch between US blue-collar suburban jobs and inner-city African Americans led to longdistance commuting and rising unemployment (Bi et al., 2019; Hu, 2015; Liu \& Kwan, 2020). Most

Copyright 2022 Yongling Li, Stan Geertman, Yanliu Lin, Pieter Hooimeijer, Wangtu Xu \& Jie Huang http://dx.doi.org/10.5198/jtlu.2022.1884

ISSN: $1938-7849$ | Licensed under the Creative Commons Attribution - Noncommercial License 4.0

The Journal of Transport and Land Use is the official journal of the World Society for Transport and Land Use (WSTLUR) and is published and sponsored by the University of Minnesota Center for Transportation Studies. 
current research on spatial mismatch focuses on European and American cities or Chinese megacities, such as Beijing (e.g., Huang et al., 2019). However, the theories and findings of these studies may not be directly applicable to other Chinese cities, because the contextual conditions can be very different. For instance, ethnic groups in US cities experience a higher degree of spatial mismatch than whites (Stoll, 2006). But whether disadvantaged groups (such as migrant workers) are the groups that experience the greatest in spatial mismatch is controversial in China. One example can be seen in Fan et al. (2014) in which migrant workers in Beijing experienced a higher degree of spatial mismatch than local workers. In contrast, Huang et al. (2018) found that in Beijing, many migrants can easily adapt to their new circumstances by changing jobs to reduce their degree of spatial mismatch. Although the research on Cities such as Beijing or Shanghai is of great significance, as a nation's cultural, educational, and political center, they gather different types of population and industries and may be different from cities of other scales in terms of spatial structure. Therefore, the results from these megacities cannot be applied directly to other cities. However, until now, the spatial mismatch for various socioeconomic groups in Chinese cities of other scales (other than megacities) has not been investigated explicitly. To fill this gap, the present research examined the spatial mismatch for distinct socioeconomic groups in Xiamen city. Xiamen is one of the first places where the danwei system collapsed as a result of the economic reform, and the disintegration of the danwei system is often seen as one of the main reasons for spatial mismatch in China (e.g., Fan et al., 2014; Liu \& Chai, 2015). Danwei—or work unit—refers to an institution that provides urban residents with housing and educational, cultural, health, and other welfare facilities (Chai, 1996). In 2015, only 1\% of the population of Xiamen was still living in danwei housing (Xiamen Urban Planning and Design Research Institute, 2015).

When studying spatial mismatch, the first step is to measure the degree of spatial mismatch. Methods to calculate this degree can be broadly summarized into three categories, namely those that use commuting time/distance, the dissimilarity index, or job accessibility (Qi et al., 2018). For commuting time/distance, one can analyze the relationship between independent variables and commuting time at the individual level; however, one cannot describe spatially which locations have the greatest spatial mismatch. In the case of the dissimilarity index, one describes the degree of imbalance between jobs and housing within a region or city (Hu et al., 2017 ). However, as $\mathrm{Hu}$ (2015) argued, this index does not indicate the spatial disparities at the disaggregated level. In this regard, the third measurement-job accessibility-is usually employed (e.g., Hu, 2015; Hu et al., 2017).

In the study of social equity, spatial mismatch emphasizes the imbalance in the distribution of disadvantaged groups and employment, and job accessibility is used as an indicator to determine the extent to which workers can access jobs by a certain travel mode within a fixed time threshold (Fan et al., 2014). But this method does not consider competition between subgroups. For example, if there are 1,000 blue-collar jobs available and 1,000 blue-collar local workers and 1,000 blue-collar migrant workers, the supply (i.e., blue-collar jobs) and demand (i.e., local blue-collar workers) are regarded as balanced, ignoring the competition from blue-collar migrant workers and the resulting spatial mismatch. In order to solve this deviation in the calculation of spatial mismatch when certain types of jobs or workers are divided into sub-categories, in the present research the dissimilarity index was optimized so that it could indicate the spatial disparities of local and migrant workers.

This paper is structured as follows. Section 2 reviews spatial mismatch for different socioeconomic groups in China. Section 3 describes the data sources and methodology, including the data collection and management, as well as the implementation of a geographic information system (GIS). Section 4 presents the results of the analysis; that is, the spatial mismatch for different socioeconomic groups in Xiamen city. Section 5 concludes the paper and discusses policy implications. 


\section{$2 \quad$ Literature review}

\subsection{Spatial mismatch in China}

Spatial mismatch refers to the discrepancy between where people work and where they live. The first study on spatial mismatch explored how the suburbanization of jobs contributed to high levels of unemployment among African Americans living in inner cities (Kain, 1968). There is renewed policy interest in spatial mismatch issues in China since emerging research shows that spatial mismatch is a growing problem. Several potential causes of this have been identified.

Some scholars have pointed to the disintegration of the danwei system as one of the main causes of the spatial mismatch in China (Fan et al., 2014; Liu \& Chai, 2015). Before the housing reforms in 1998, danwei provided people with not only employment but also housing and various facilities. Life within the danwei system was convenient, as employees' economic, political, and social lives were all within the walls of the danwei community (Li \& Kleiner, 2001). As jobs and housing were well balanced in this system, commuting distances were relatively short (Chai, 1996; Chai et al., 2011). The disintegration of the danwei system as part of the housing reforms separated economic activities and individuals' daily activities, leading to spatial dispersion and differentiation (Chai et al., 2011). As a consequence, growing numbers of urban residents bought houses in the private market, which resulted in a further separation of workplace and place of residence (Chai et al., 2007).

Another potential cause of spatial mismatch is the large-scale urbanization that has arisen as a result of China's market-oriented economic reforms. The eastern coastal cities and special economic zones (SEZs) that were opened up to overseas investment during the 1980s are new places of economic growth and population concentration. Since then, these coastal cities — which include Xiamen - have attracted millions of mostly rural migrants to work in the newly established manufacturing industries (Liu \& Chai, 2015). The proportion of migrants in eastern Chinese cities increased from $38.48 \%$ in 1982 to $64.60 \%$ in 2005 (Duan \& Yang, 2009). Cities expanded into huge industrial sites, leading to drastic spatial restructuring (Liu \& Chai, 2015). Over the last 10-15 years, there has been a decentralization of industry and construction jobs from central business districts to the outskirts of cities due to much cheaper land prices, while the rapidly growing service sector has quickly filled the leftover spaces in the central business districts.

The rapid expansion of these SEZs and eastern coastal cities has caused varying degrees of spatial mismatch between different types of workers and their corresponding jobs. As Kain (1968) indicated, the level of spatial mismatch varies between occupations and industries. In Kain's findings, this difference is mainly reflected in blue-collar jobs (e.g., those performed by craftsmen, machine operatives, and laborers) and other jobs (e.g., managerial, technical, official, professional, clerical, and sales jobs). Unequal spatial distribution of skill requirements and residential segregation exacerbates this mismatch. Similarly, Fan et al. (2014) found that the level of spatial mismatch in Beijing varies between occupations. Specifically, the spatial mismatch for blue-collar workers is greater than that for pink-collar workers.

Another important finding by Fan et al. (2014) is that the spatial mismatch for migrant workers is greater than that for local workers. In the past, the urban household registration system (bukou) limited inter-city population flows (Chai, 1996). Housing reforms coupled with rapid urbanization have prompted a massive influx of migrants into these SEZs and eastern coastal cities. These migrant workers, who do not possess local hukous, cannot access the government-subsidized affordable housing system (Fan, 2002). Consequently, a big distinction emerged between local workers and migrant workers in terms of housing and job accessibility. For instance, low-income local workers can apply for affordable public housing, which is mainly located on the urban fringes and has poor access to jobs and facilities 
(Zhou et al., 2013). In contrast, most low-income migrants are excluded from affordable public housing in the city and rent private housing, notably rooms, in "urban villages," which are often located quite close to and/or even incorporate low-income job opportunities and other facilities (Hao et al., 2012, 2013; Lin et al., 2014). Other reasons for migrants to rent housing in urban villages are the low rents and the "network effect" of being well-informed of work opportunities (Zhu et al., 2017). This suggests that different hukou holders have settled in different parts of the city and experience distinct forms and degrees of spatial mismatch.

Given these differentiations within the phenomenon of spatial mismatch, following Qi et al. (2018) we defined spatial mismatch in the present research as a mismatch for any specific population group between where they live and where their suitable and accessible job opportunities are located. Differences between occupations (e.g., blue-collar, pink-collar, and white-collar work) and between hukou status (e.g., local population and migrant population) may cause differences in the degree of spatial mismatch (Fan et al., 2014). Therefore, we distinguished different groups based on occupation and hukou. Bluecollar workers perform non-agricultural manual labor in, for example, manufacturing, mining, construction, mechanical engineering, maintenance, or warehousing, whereas pink-collar workers perform service-oriented clerical jobs, such as customer interaction, entertainment, or sales (Fan et al., 2014). White-collar workers have high-education occupations; they work in offices or other administrative settings, doing professional or administrative work.

\subsection{Measurement of spatial mismatch}

Several attempts have been made to use commuting time to test the spatial mismatch hypothesis (e.g., Haddad, 2020; Zhao et al., 2011). These studies were generally based on individual-level commuting data derived from surveys and used statistical analysis (e.g., regression models) to measure the impact of different independent variables on commuting time. The research that took commuting time as the dependent variable can be subdivided into two categories. The first category used job accessibility as an independent variable to study its impact on commuting time (e.g., Zhao, 2015), while the second category used travel time as an indicator of spatial mismatch in analyzing whether a specific group has a longer travel time than other groups (Haddad, 2020; Zhou et al., 2016). These studies analyzed and compared the relationship between independent variables and commuting time at the micro levels, but failed to describe which locations have the greatest spatial mismatch.

Another commonly used indicator is the dissimilarity index. This index was traditionally used to measure the degree of housing segregation between different races within a city or region and was later used in the study of spatial mismatch to measure the imbalance in the housing and jobs of disadvantaged groups. For instance, Liu and Painter (2012) used the dissimilarity index as a measure of spatial mismatch to measure the imbalance between residential and employment distribution. Qi and Fan (2018), however, argued that the original index - which assumed that spatial interaction did not depend on distance or that spatial interaction would continuously decrease as distance increased — was problematic for measuring the spatial mismatch for disadvantaged groups in China, whose main commuting mode is public transportation. They therefore extended the dissimilarity index by measuring the imbalance between residential distribution and employment that is accessible by public transportation. However, while the index can calculate the overall degree of spatial mismatch in a large region, it cannot indicate the spatial disparities at the disaggregated level.

The last commonly used indicator is job accessibility, which identifies the degree of spatial mismatch for each spatial unit. Among the numerous accessibility calculation methods, Shen's (1998) relative gravity-based job accessibility model is the most commonly used in studies of spatial mismatch (e.g., Hu, 2015; Hu et al., 2017 ). This is because Shen's measures incorporate all three factors of spatial 
mismatch, namely the location and number of vulnerable groups, the location and number of their jobs, and the commuting time between the two locations. However, as described in the introduction, although this method is effective when the total number of jobs and the total number of workers are roughly the same, a certain degree of calculation bias will arise in the case of subcategorization.

To address the spatial mismatch problem when certain types of jobs or workers are further divided into sub-categories, we optimized the dissimilarity index so that it can not only measure the spatial mismatch for a certain sub-category of workers, but also reflect the spatial disparity in a larger range.

\section{$3 \quad$ Methodology}

\subsection{Study area}

Xiamen is a hub city in the southeast of Fujian Province. It has six districts: two inner districts (Siming and Huli) and four outer districts (Haicang, Jimei, Tong'an, and Xiang'an). The urbanized area has spread from the original island (Siming and Huli districts) to the other four districts; between them, the six districts cover nearly 1,700 square kilometers (Figure 1). The Xiamen Special Economic Zone (SEZ) was one of the first four SEZs to be created as part of China's opening-up process in the early 1980s. In 1980, the State Council approved the establishment of a 2.5 square kilometer SEZ in Xiamen. After China's then-paramount leader Deng Xiaoping visited Xiamen in 1984, the SEZ was extended to cover the whole island (131 square kilometers). The State Council then successively approved the establishment of Taiwanese investment zones in Haicang, Xinglin, and Jimei, and implemented the existing policies for the SEZs. In 1992, it also approved the establishment of the Xiangyu Free Trade Zone.

In 2017, the population of Xiamen reached 4 million people, of whom 2.3 million held Xiamen local hukous, enabling them to enjoy various benefits. For instance, their children can be enrolled in public schools; they are eligible to apply for affordable housing and low-rent housing and for entrepreneurial interest-free loans; and they get high-value medical social insurance and welfare. Migrants without local hukous do not enjoy these benefits (Hu et al., 2017).

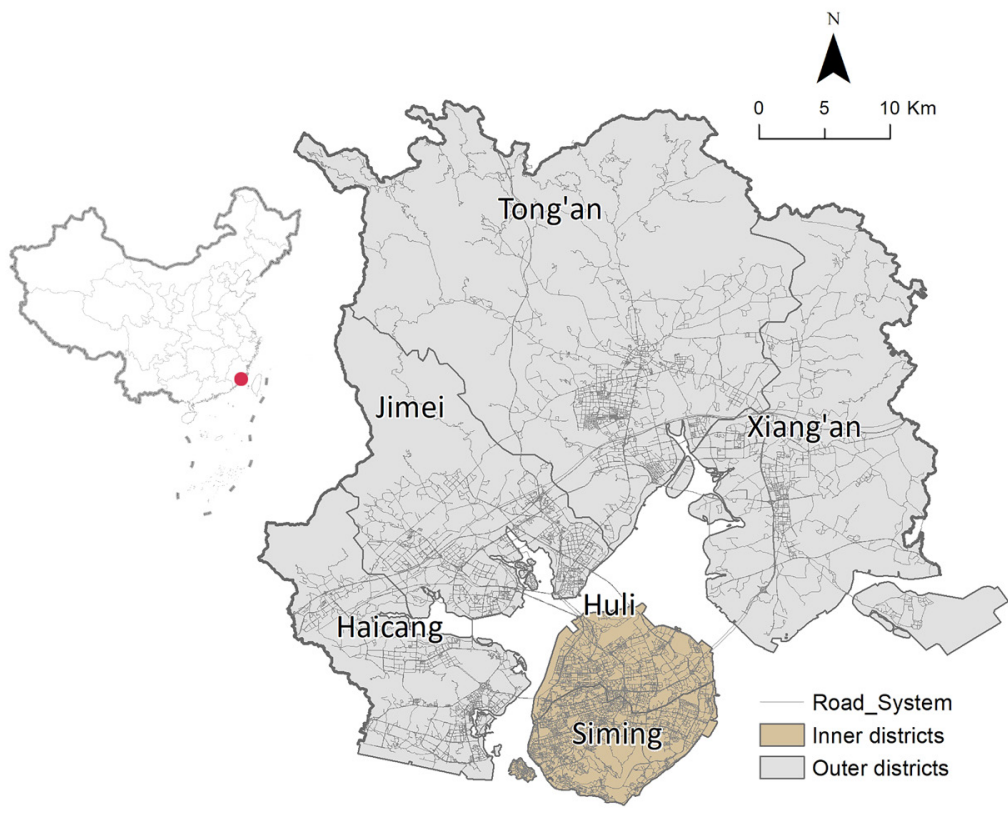

Figure 1. Districts and areas of Xiamen city 


\subsection{Data collection and classifications of different socioeconomic groups}

Travel time matrix data (real-time travel data) were obtained from the Gaode Maps application programming interface (Gaode API), which is a set of application programming interfaces written in JavaScript. It contains basic functional interfaces for building maps and providing data services, for example, for local search and route planning. In order to deal with the differences in return time results at different times of the day, we set the departure time at 08:00. We used a 1000*1000 square meter grid as our basic unit, and obtained the travel time matrix between each unit from the Gaode API. We chose the urban built-up area of Xiamen as the research area, rather than the entire administrative area, and only selected grids with a population of more than 1,000 people.

Socioeconomic and travel data were drawn from the 2015 Xiamen household travel survey. These data cover $3 \%$ of the total population of Xiamen and include trip mode, trip purpose, travel time, origin, destination, etc. Socioeconomic data include age, gender, occupation, education level, housing attribute, car ownership, etc.

Previous studies often used income, education level, and skills as indicators of disadvantaged workers (Fan et al., 2014; Hu et al., 2017 ). In line with the classification developed by Fan et al. (2014), we divided jobs and workers into blue-collar jobs/workers, pink-collar jobs/workers, and white-collar jobs/ workers. Both blue-collar and pink-collar workers are regarded as having low-education occupations (Appendix I). Blue-, pink-, and white-collar workers comprised 16\%, 31\%, and 53\%, respectively, of our sample.

Employment data for 2012, comprising 65,891 firm records and 2,026,217 job records, were obtained from Xiamen Municipal Bureau of Commerce. The jobs were categorized into 19 economic sectors. based on the classification developed by Fan et al. (2014), the jobs were further categorized into blue-collar, pink-collar, and white-collar jobs (Appendix II). In our data, blue-, pink-, and white-collar jobs comprised $56 \%, 32 \%$, and $12 \%$, respectively, of the jobs.

\subsection{Measuring job accessibility}

To measure job accessibility, we applied a cumulative opportunity approach (Geurs \& van Wee, 2004; Hernandez, 2018), which defines travel mode and travel time, and then counts the number of jobs reachable via that mode within that travel time. This approach uses ArcGIS, Python, and MySQL for data collection, analysis, and management. It comprises five steps.

\section{Step 1: Define travel mode, threshold travel times, and decay function}

In Xiamen, walking and public transportation are the dominant travel modes, accounting for $30.3 \%$ and $25.7 \%$, respectively, of all trips in 2015 . Cumulative frequency analysis showed that $75 \%$ of the working population traveled for less than 50 minutes by public transportation and less than 20 minutes on foot (Figure 2). We therefore defined the threshold time as 50 minutes for public transportation and 20 minutes for walking. We calculated different distance-decay coefficients for walking and public transportation. As shown in Figure 3, the distance-decay coefficient of walking is -0.050 , and that of public transportation is -0.015 . 

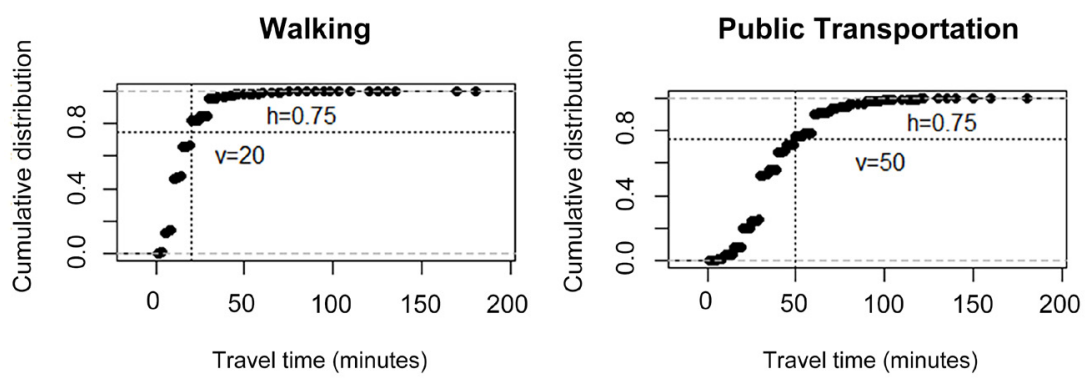

Figure 2. Cumulative frequency of travel time for (a) walking and (b) public transportation

Walking

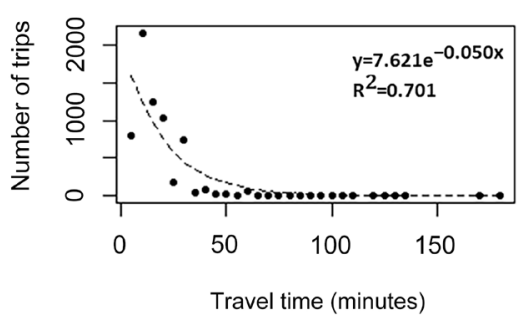

Public Transportation

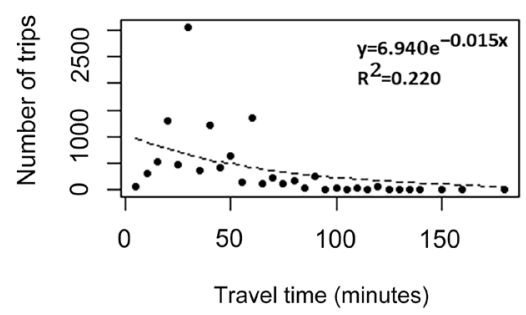

Figure 3. Decay function with time impedances for (a) walking and (b) public transportation.

\section{Step 2: Define the basic unit within a GIS environment}

Previous studies used traffic analysis zones (TAZ) or administrative districts (jiedao) (Fan et al., 2014; Hu et al., 2017 ) as their basic units. However, the average size of a TAZ in Xiamen is 9.2 square kilometers, which is too big to produce accurate results. Apparicio et al. (2008) concluded that in order to increase accuracy, smaller spatial units should be used. Consequently, and as mentioned, we used $1000^{*} 1000$ square meters as the basic spatial unit in our analysis. We only selected populated built-up areas as research units, since it would have been meaningless to measure accessibility for non-built-up areas (or areas with sparse populations).

\section{Step 3: Obtain travel time matrix by using Python and MySQL}

In order to measure the travel time by different transportation modes, we used the Python programming language to collect the travel time matrix data for different transportation modes from the Gaode Maps (AMap) Geocoding API. We calculated the latitude and longitude of the grid centroid and used the API to obtain the travel time and travel distance between each grid. We chose "Minimize travel time between an origin and a destination" as our best-path algorithm option. We set the departure time at 08:00 to avoid the difference in return time results at different times of the day.

\section{Step 4: Calculate job accessibility}

Finally, we calculated job accessibility $A_{i}^{m}$ by travel mode $m$ :

$\left.A_{i}^{T m}=\sum_{i \in\left\{d_{i j} \leq d_{0}\right\}}\right\}_{j}^{T m} f_{t}\left(t_{i j}\right)$

Where $A_{i}^{m}$ represents job accessibility of work type $T$ by travel mode $m$ at grid $i ; J_{j}^{m}$ is the number 
of jobs of type $T$ that can be accessed by travel mode $m$ at location $j$ within the threshold travel time of $i\left(d_{i j} \leq d_{0}\right)$; and $f^{t m}\left(t_{i j}\right)$ is the decay function of travel time by travel mode $m$ :

$$
f^{t m}\left(t_{i j}\right)=e^{\beta^{t m}} t_{i j}
$$

where $\beta^{\text {tm }}$ is the decay coefficient by mode $m$ and $t_{i j}$ denotes travel time between location $i$ and location $j$.

\subsection{Estimation of spatial mismatch}

To measure spatial mismatch between job accessibility and residential distribution, we calculated the difference between them in each grid unit. The formula is:

$$
S_{i}^{t m}=\frac{P_{i}^{t}}{\sum_{i=1}^{n} P_{i}^{T}}-\frac{\sum_{i=1}^{n} P_{i}^{t}}{\sum_{i=1}^{n} P_{i}^{T}} * \frac{A_{i}^{T m}}{\sum_{i=1}^{n} A_{i}^{T m}}
$$

Where $S_{i}^{t m}$ refers to the difference between accessibility of type $T$ jobs by travel mode $m$ and residential distribution of type $t$ workers at location $i$.

Unlike previous studies (e.g., Fan et al., 2014), the spatial mismatch measured by distinguishing different types of occupations and workers (i.e., blue-collar, pink-collar and white-collar) also incorporates competition between locals and migrants. In other words, the corresponding jobs must be allocated to the corresponding local workers and migrant workers in accordance with the ratio of local workers and migrant workers. $P_{i}^{T}$ represents the sum of local and migrant workers of type $T$ at location $i$ and $P_{i}^{t}$ represents either local or migrant workers of type $T$ at location $i$.

\section{$4 \quad$ Results}

The method discussed in Sections 3.3 and 3.4 was used to identify the accessibility of different types of jobs and the degree of spatial mismatch for the corresponding workers. As mentioned, in our data, blue-, pink-, and white-collar jobs comprised $56 \%, 32 \%$, and $12 \%$, respectively, of the jobs, while blue-, pink, and white-collar workers comprised $16 \%, 31 \%$, and $53 \%$, respectively, of the workers. Thus, jobs and workers do not correspond exactly and a certain percentage of white-collar workers may be employed in blue-collar and pink-collar jobs. The following subsections present a spatial mismatch assessment by groups. 


\subsection{Blue-collar workers' residences and jobs}
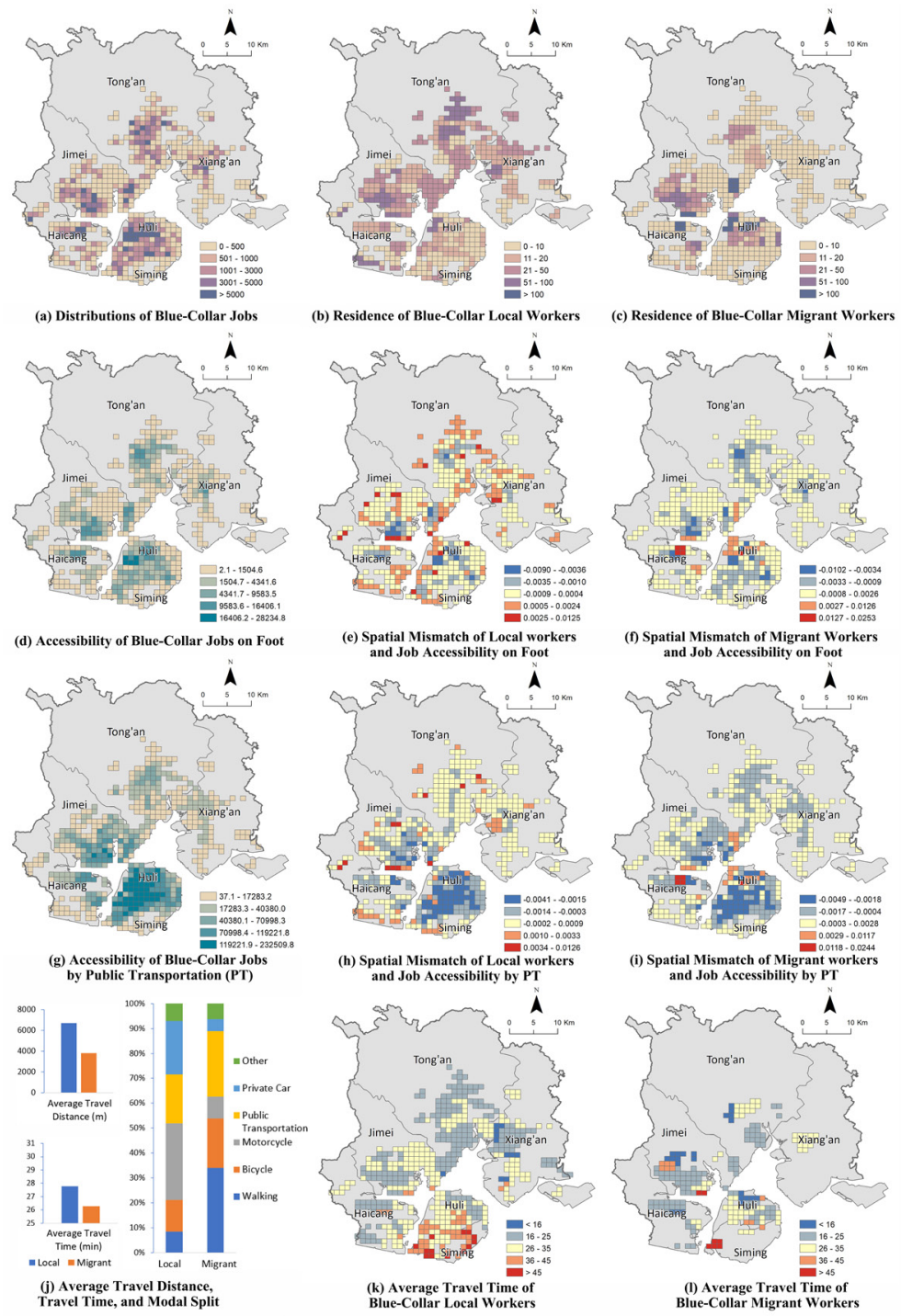

Figure 4. Spatial mismatch between blue-collar workers' residences and jobs

With regard to the spatial distribution of residents, there is a considerable difference between bluecollar local workers (workers with Xiamen hukous) and blue-collar migrant workers (workers without Xiamen hukous). Concentrations of blue-collar local workers' homes can be found particularly in the outer districts, and especially on the urban fringe. In the recent past, these were farmers living in the villages on the urban fringe of Xiamen city. Many of them now work in the industrial or service sector, while still living in their original houses in the villages. In contrast, most blue-collar migrants live in urban villages, which are mostly located close to the industrial areas.

Regarding blue-collar jobs that can be reached on foot, the spatial pattern presents a polycentric structure with five centers: one in Huli district, where a tariff-free zone and high-tech industry are located; one in Haicang district, where heavy industry is located; two in Jimei district, where the Taiwanese investment zones are located; and one in Tong'an district, where heavy industry is located. These five centers are large industrial zones that were built following the transformation of Xiamen from an "island 
city" in the 1980s to an "island-gulf city" in the 1990s.

In terms of the spatial mismatch for local workers and migrant workers, in general, public transportation greatly improves employment accessibility. Correspondingly, the negative value (blue color) in Figures 4(h) and 4(i) (more jobs than workers) is greater than that in Figures 4(e) and 4(f), while the positive value (red color) in Figures 4(h) and 4(i) (more workers than jobs) is smaller than that in Figures 4(e) and 4(f). For blue-collar local workers, the spatial mismatch mainly occurs in the outer urban areas, partly on the southwest coast of Siming District. For blue-collar migrant workers, the spatial mismatch mainly occurs in Haicang, Huli, and Jimei, where migrant workers are the most concentrated. In general, the spatial mismatch for local workers is greater than that for migrant workers, which is also reflected in the fact that the average travel distance and travel time of the former are much longer than those of the latter.

In order to examine whether the spatial mismatch caused the longer travel time, we compared Figures 4(h) and 4(i) with Figures $4(\mathrm{k})$ and 4(l). It should be noted that when calculating the average travel time for each spatial unit, we only selected grids with a cumulative number of trips $>5$ to avoid the extreme values caused by only one or two trips in some grids. In general, the grids in which job and worker distribution are reasonably balanced (the yellow parts in Figures 4(h) and 4(i)) tend to have the lowest average travel time (the blue parts in Figures $4(\mathrm{k})$ and $(\mathrm{l})$ ).

Contrary to our expectation, areas with more workers than jobs do not have increased travel times, and areas with far more jobs than workers do not have reduced travel times. In terms of local workers, although the peripheral areas have fewer jobs than workers, the average travel time is short, while in the inner urban areas where there are more jobs than workers, the average travel time is relatively long (Figure $4(\mathrm{k})$ ). This is mainly caused by the difference in travel mode between residents in the inner districts and those in the outer districts. In the inner districts, public transportation is the main mode of commuting, with about $40 \%$ of blue-collar local workers commuting by public transportation. On the other hand, only $10 \%$ of blue-collar local workers in the outer districts use public transportation. Instead, most of them use private cars or motorcycles to commute, thereby reducing their commuting time. As for migrant workers, the comparison between Figure 4(i) and Figure 4(l) shows that the average travel time in those sparsely populated areas is relatively long, while the average travel time is short in the areas where migrant workers are concentrated. In general, the average travel time is longer in areas with few blue-collar workers, especially in Siming District, because most blue-collar jobs are located in the outer districts and northern Huli District. 


\subsection{Pink-collar workers' residences and jobs}
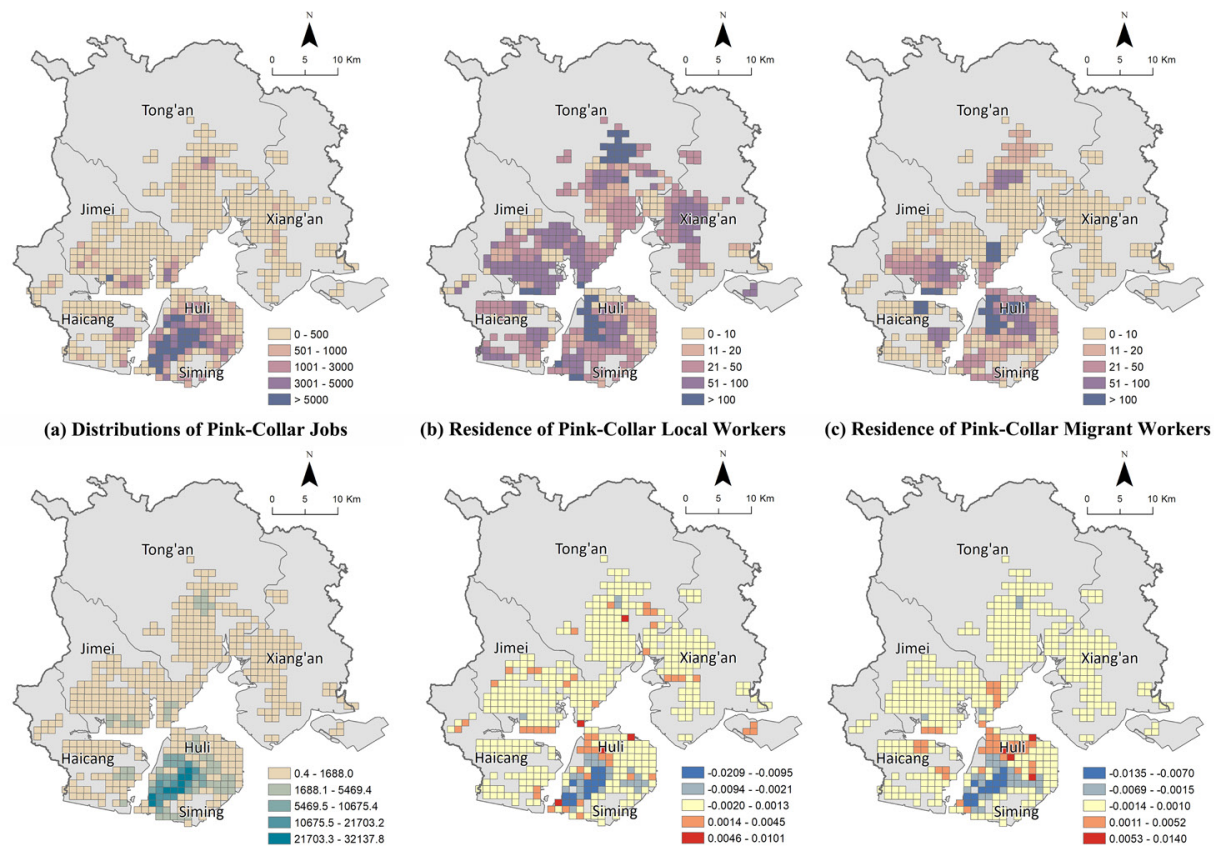

(b) Residence of Pink-Collar Local Workers

(c) Residence of Pink-Collar Migrant Workers

(d) Accessibility of Pink-Collar Jobs on Foot
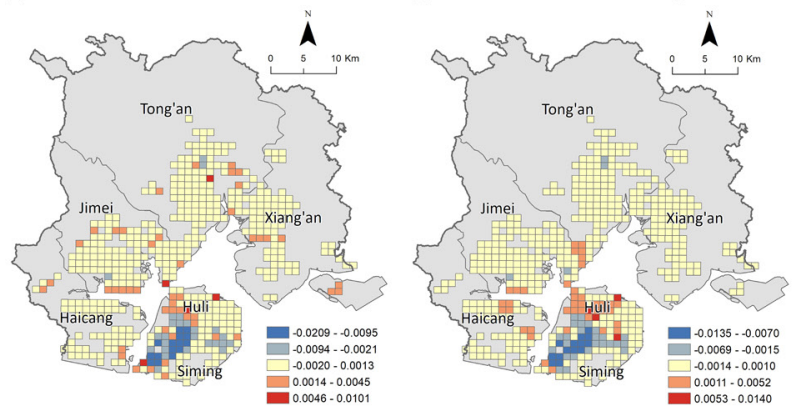

(e) Spatial Mismatch of Local workers and Job Accessibility on Foot
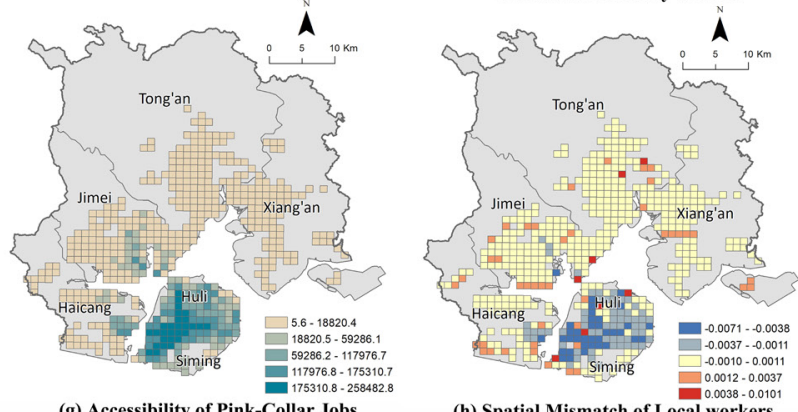

(f) Spatial Mismatch of Migrant Workers and Job Accessibility on Foot (g) Accessibility of Pink-Collar Jobs
by Public Transportation (PT)

(h) Spatial Mismatch of Local workers and Job Accessibility by PT

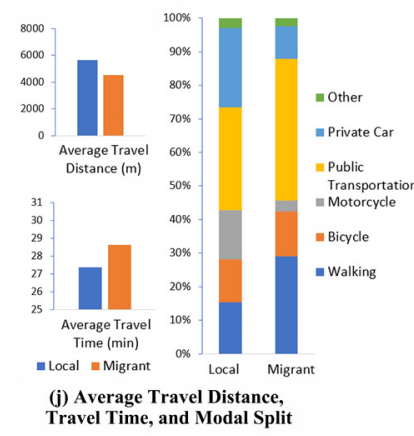

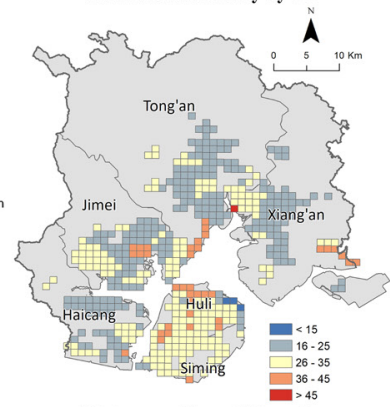

(k) Average Travel Time of

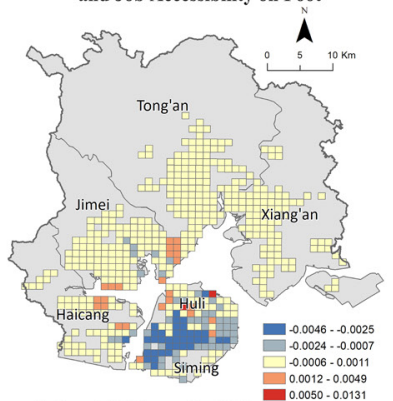

(i) Spatial Mismatch of Migrant workers and Job Accessibility by PT

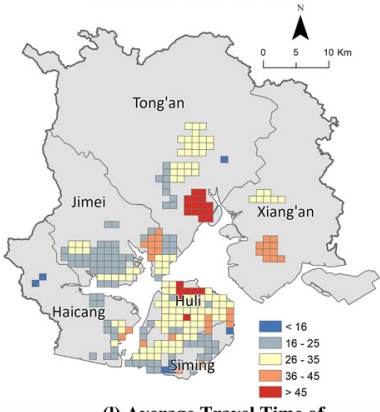

(l) Average Travel Time of Pink-Collar Migrant Workers

Figure 5. Spatial mismatch between pink-collar workers' residences and jobs

Regarding the spatial distribution of residences, a considerable distinction between pink-collar local workers and pink-collar migrant workers can be seen (Figures 5(b) and 5(c)). The residential spatial pattern of pink-collar locals is relatively more dispersed than that of pink-collar migrants. There are two main reasons for this. First, the farmers (locals) in the former villages on the urban fringe of the city switched to work in non-agricultural sectors, doing both blue-collar and pink-collar jobs. Second, also other low-educated locals across the city engage in pink-collar jobs because of their low-skill demands. 
In contrast, like blue-collar migrants, pink-collar migrants live primarily in urban villages, most of which are quite centrally located near employment concentrations.

With respect to the accessibility of pink-collar jobs on foot, a huge concentration can be found on Xiamen Island. This area is packed with tourist attractions and commercial sites, and both locals and tourists engage in business and leisure activities here. Accordingly, this centrally located area aggregates a range of personal-service-oriented jobs. With respect to the accessibility of pink-collar jobs by public transportation, most of Xiamen Island (Siming and Huli districts) is highly accessible, indicating that the efficient public transportation system on the island greatly improves the accessibility of this area.

For local pink-collar workers, spatial mismatch with fewer job opportunities than workers mainly occurs in some scattered areas. In comparison to blue-collar local workers, the spatial mismatch for pinkcollar local workers is not as great, partly reflecting that the former's average travel distance $(6700 \mathrm{~m})$ is longer than the latter's $(5600 \mathrm{~m})$. For pink-collar migrant workers, similar to blue-collar migrants, the spatial mismatch mainly occurs in areas with a high concentration of migrant workers in Haicang, Huli, and Jimei. Compared with blue-collar migrant workers, the spatial mismatch for pink-collar migrant workers is slightly greater, which is partly reflected in the fact that the former's average travel distance $(3800 \mathrm{~m})$ is greater than the latter's (4500 m). Comparing local and migrant groups of pink-collar workers, we can see that the spatial mismatch for local workers is greater than that for migrant workers, which is also reflected in the fact that the former's average travel distance is longer than the latter's. Nevertheless, due to the differences in their travel modes, the average travel time of the former is shorter than that of the latter.

Since the proportion of public transportation trips is greater than walking for both local and migrant workers, we chose Figures 5(h) and 5(i) as the spatial mismatch for local and migrant workers, respectively. Accordingly, we compared Figures 5(h) and 5(i) with Figures 5(k) and 5(l) to examine whether the spatial mismatch caused the longer travel time. Again, the grids with basically a balanced job-worker distribution tend to have the lowest average travel time. For both local and migrant workers, there is insufficient evidence that the spatial mismatch calculated by potential job accessibility has caused an increase in actual commuting time. Those grids with a relatively long average travel time tend to be in areas with more jobs than workers or a balance between jobs and workers. However, a comparison between the distribution of workers (Figures 5(b) and 5(c)) with the average travel time distribution (Figures 5(k) and 5(l)) shows that the average travel time in the relatively sparsely populated areas is longer. This result is consistent with the situation of blue-collar workers.

\subsection{White-collar workers' residences and jobs}

In terms of white-collar workers, we found that local workers and migrant workers differ substantially in their residential distribution (Figures 6(b) and 6(c)). White-collar locals reside relatively homogeneously across the city, while the homes of white-collar migrants are quite concentrated in certain places. Most white-collar migrants live in places that have been redeveloped or are located in newly built areas near the urban villages. Their distribution is similar to the distribution of blue-collar and pink-collar workers. This result shows that migrant workers tend to agglomerate, mainly in a few specific areas.

With respect to the accessibility of white-collar jobs on foot, like pink-collar jobs, a huge concentration of white-collar jobs can be found on Xiamen Island, where Xiamen's central business district is located. With respect to the accessibility of white-collar jobs by public transportation, these jobs are highly accessible from most areas of Xiamen Island (Siming and Huli districts), indicating that the efficient public transportation system on the island greatly improves the accessibility of these jobs. 


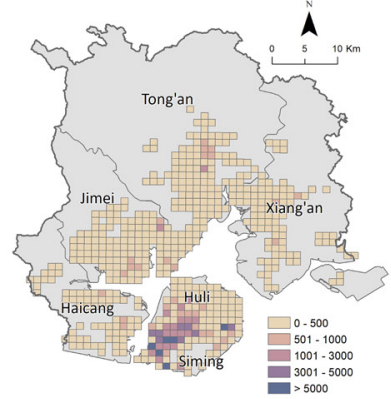

(a) Distributions of White-Collar Jobs

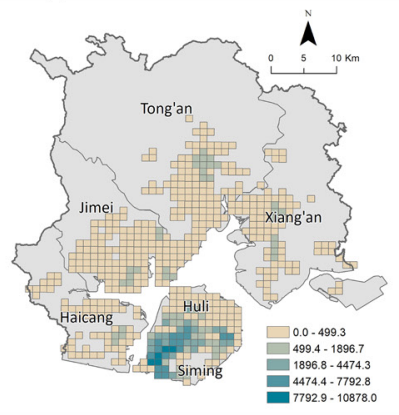

(d) Accessibility of White-Collar Jobs on Foot

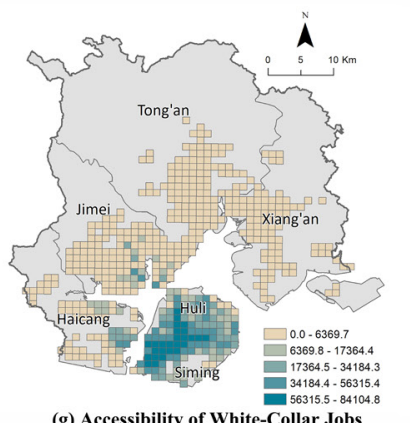

g) Accessibility of White-Collar Jobs

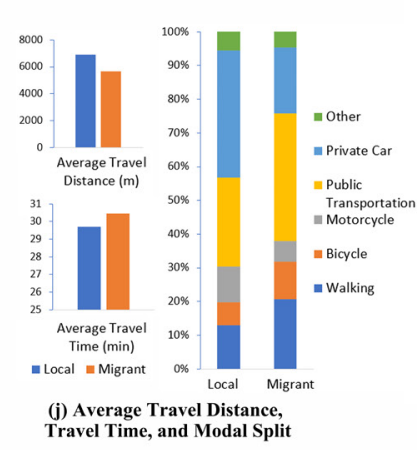

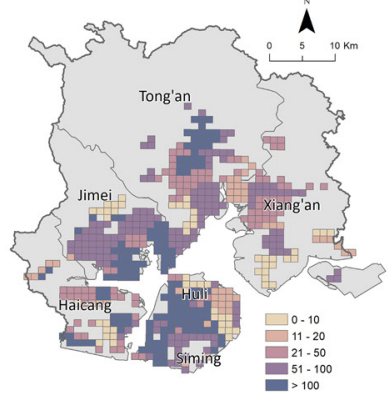

(b) Residence of White-Collar Local Workers

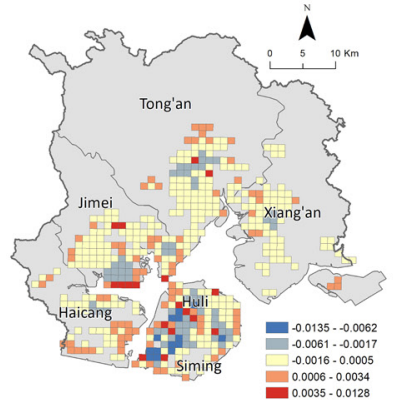

(e) Spatial Mismatch of Local workers

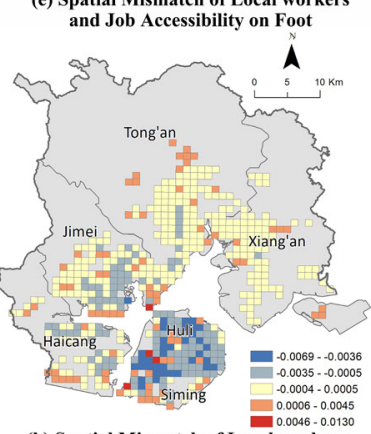

(h) Spatial Mismatch of Local workers and Job Accessibility by PT

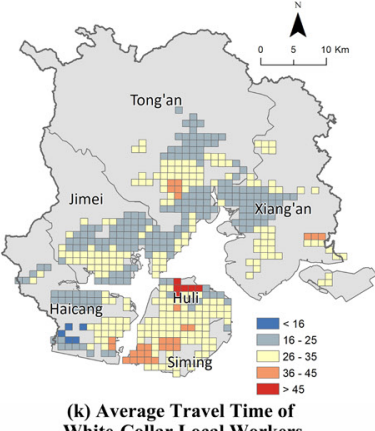

White-Collar Local Workers

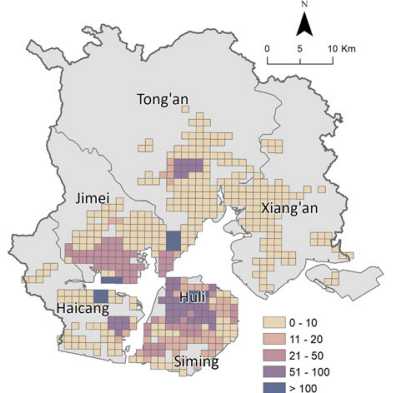

(c) Residence of White-Collar Migrant Workers

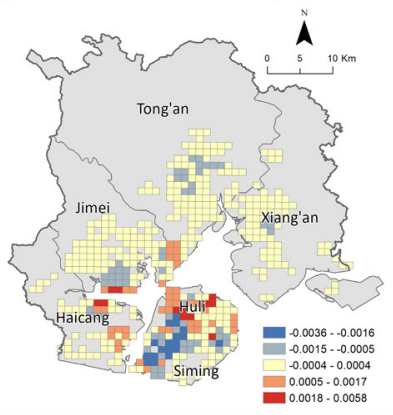

(f) Spatial Mismatch of Migrant Workers

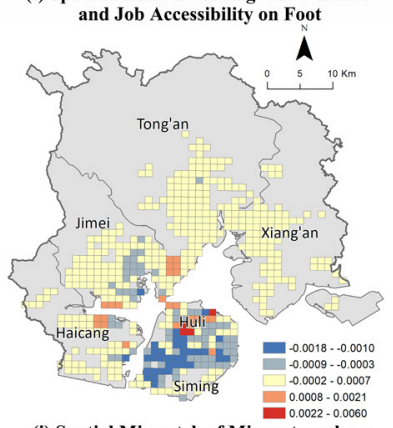

(i) Spatial Mismatch of Migrant workers

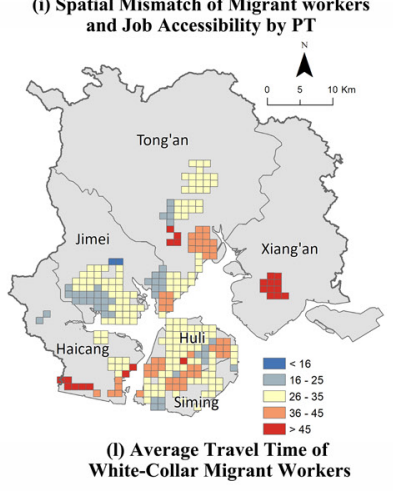

Figure 6. Spatial mismatch between white-collar workers' residences and jobs

For white-collar local workers, the spatial mismatch with fewer jobs than workers mainly occurs in the outer areas (Figures 6(h)). Compared with blue- and pink-collar local workers, the degree of spatial mismatch for white-collar local workers is the largest, reflected in the longest average travel distance $(6900 \mathrm{~m})$. For white-collar migrant workers, as for other types of migrants, the spatial mismatch mainly occurs in areas with a high concentration of migrant workers in the districts of Haicang, Huli, and Jimei. Compared with blue- and pink-collar migrant workers, the spatial mismatch for white-collar migrant workers is greater and the average travel distance is the longest $(5700 \mathrm{~m})$. Again, the spatial mismatch 
for local workers is greater than that for migrant workers. However, as in the case of pink-collar workers, the average travel time of the local workers is shorter than that of migrant workers due to differences in their travel modes.

Considering their preferred mode of travel, we compared Figures 6(h) and 6(i) with Figures 6(k) and 6(l) to examine whether the spatial mismatch caused longer travel times. The results show that grids with a balanced jobs-workers distribution tend to have the lowest average commuting time. We found that inner districts, where the number of available jobs vastly outnumbered the population, were areas with longer average commutes. This is mainly because the high density of the inner city can support a denser bus network and a higher bus frequency, and therefore people in the inner city are more inclined to use public transportation for commuting, which leads to longer commuting times. Consistent with the results for blue- and pink-collar migrant workers, areas where white-collar migrant workers have longer average commuting time tend to be relatively sparsely populated. On the contrary, the average commuting time in places where migrant workers are concentrated is relatively short. This is due to the fact that the majority of the migrant workers are renters and thus has greater flexibility in their housing choice and tends to live closer to the place of work.

\section{$5 \quad$ Conclusions and discussion}

The present research took Xiamen city in China as a case study to analyze the degree of spatial mismatch for different socioeconomic groups. It contributes to previous research by differentiating between groups of workers according to socioeconomic status and hukou status.

We optimized the dissimilarity index to identify spatial differences within the city. This resulted in three major findings:

- Blue-collar, pink-collar, and white-collar workers, who are further categorized as either locals or migrants, experience varying degrees of job accessibility and spatial mismatch. In general, the degree of spatial mismatch is greater for blue-collar and pink-collar locals than it is for bluecollar and pink-collar migrants. Most blue-collar locals live outside Xiamen Island, in particular on the urban fringes. The main reason for this is their background as farmers and the high prices of apartments on the island. The spatial residential pattern of pink-collar locals is relatively dispersed. In contrast, both blue-collar and pink-collar migrant workers tend to rent rooms or apartments in one of the urban villages. They are thus much more flexible than local homeowners and can easily adjust where they live to changes in where they work. Moreover, most of the urban villages encompass or are located near industrial or central service areas. In other words, most blue-collar and pink-collar migrants live close to where they work. As a result, the spatial mismatch for both blue-collar and pink-collar migrants is much less than for blue-collar and pink-collar locals. For white-collar jobs and workers, there are differences in residential distribution between locals (whose homes are more evenly dispersed) and migrants (whose homes are more concentrated), while most of their jobs are distributed in Xiamen Island. Furthermore, white-collar local workers suffer a greater spatial mismatch than white-collar migrant workers.

- Despite the greater spatial mismatch, the commuting time of local workers (especially pinkand white-collar workers) is shorter than that of their migrant counterparts. This is due to the difference in transportation modes between local and migrant workers. In general, local workers use private cars more often than migrant workers, which can reduce their travel time to a certain extent. Thus, although migrant workers have advantages over local workers in terms of the spatial relationship between employment and residence, they have disadvantages in terms of travel time due to travel mode.

- The proportion of public transportation in the modal split in areas with higher employment 
(inner districts) is much greater than in outer districts. Although this increases the average travel time in these areas to a certain extent, people find it acceptable. For example, the average commuting time in the inner districts is longer than that in the outer districts, despite a much larger concentration of jobs there (especially pink-collar and white-collar jobs), because the main mode of motorized travel in the area is public transportation. Still, for white-collar and pink-collar workers the average commuting time in the inner districts is less than 45 minutes (except for the airport area in the northeast), which is within people's tolerance (Huang et al., 2018). In addition, areas with a longer average commuting time tend to be relatively sparsely populated. This result is particularly obvious among migrant workers, indicating that migrant workers living in sparsely populated areas cannot benefit from agglomeration, thus increasing commuting time.

The findings of this research have important policy implications for disadvantaged groups, including blue-collar and pink-collar workers, both locals and migrants:

- This research provides a helpful reference for the locational choice of affordable housing. With the increasingly limited supply of land on Xiamen Island, government-subsidized affordable housing - which is mainly targeted at low-income local residents-has primarily been built outside Xiamen Island. Given that most pink-collar and white-collar jobs are located on Xiamen Island, this exacerbates the spatial mismatch for its residents. Affordable housing should preferably be built in areas close to these white-collar or pink-collar jobs, or in areas with efficient public transportation. Suitable places include the areas around the metro stations that are being planned or are under construction, even those outside Xiamen Island but with fast connections to it.

- A large number of urban villages in Xiamen, particularly those on the island, have been or will soon be demolished as a result of the political and economic drivers for continuing redevelopment. If these demolitions continue, migrants in Xiamen will be forced to move to low-rent housing in outer urban areas, or even to other cities. The disposable income of Xiamen residents is less than that of residents of larger eastern coastal cities, such as Nanjing and Ningbo, while their consumption expenditure (especially housing expenditure) is greater, meaning that Xiamen is less attractive than the two other cities (Nanjing Municipal Bureau of Statistics, 2020; Ningbo Municipal Bureau of Statistics, 2020; Xiamen Municipal Bureau of Statistics, 2020). If Xiamen is unable to provide a large amount of low-rent housing, it may face a large migrant exodus. Therefore, the government should consider increasing the provision of and access to government-subsidized housing so that the migrant population can also enjoy preferential policies such as low-rent housing. Again, this low-rent housing should be built around metro stations to improve migrants' access to jobs or provide public rental housing in combination with the incremental upgrading of urban villages.

- Last, but not least, a certain proportion of jobs-especially pink-collar and white-collar jobsshould be distributed in the new outer city areas. If the number of people living in the outer districts increases while the number of jobs there does not, in the future there will be an increase in commuting flows between the inner district and the outer districts, which will put tremendous pressure on the bridges and tunnels connecting the inner and outer districts. These newly created jobs should also be close to metro stations to slowly reduce the dependence on cars and motorcycles in the outer districts. 


\section{Acknowledgements}

This work is financially supported by Strategic Priority Research Program of the Chinese Academy of Sciences (Grant No. XDA19040402), Youth Innovation Promotion Association of Chinese Academy of Sciences (Grant No. 2021049) and Young Elite Scientists Sponsorship Program by China Association for Science and Technology (Grant No. 2019QNRC001). 


\section{References}

Apparicio, P., Abdelmajid, M., Riva, M., \& Shearmur, R. (2008). Comparing alternative approaches to measuring the geographical accessibility of urban health services: Distance types and aggregationerror issues. International Journal of Health Geographics, 7(1), 1-14.

Bi, L., Fan, Y., Gao, M., Lee, C. L., \& Yin, G. (2019). Spatial mismatch, enclave effects and employment outcomes for rural migrant workers: Empirical evidence from Yunnan Province, China. Habitat International, 86, 48-60.

Chai, Y. (1996). Danwei-based Chinese cities' internal life-space structure - A case study of Lanzhou City. Geographical Research, 15(1), 1-15 (in Chinese).

Chai, Y., Chen, L., \& Zhang, C. (2007). Transformation of danwei system: An angle of view on city changes in China. World Reginal Studies, 16(4), 60-69 (in Chinese).

Chai, Y., Xiao, Z., \& Zhang, Y. (2011). Urban organization and planning transformation in China: A danwei perspective. Urban Planning Forum, 198(6), 28-35 (in Chinese).

Duan, C., \& Yang, G. (2009). Trends in destination distribution of floating population in China. Population Research, 33(6), 1-12 (in Chinese).

Fan, C. C. (2002). The elite, the natives, and the outsiders: Migration and labor market segmentation in urban China. Annals of the Association of American Geographers, 92(1), 103-124.

Fan, Y., Allen, R., \& Sun, T. (2014). Spatial mismatch in Beijing, China: Implications of job accessibility for Chinese low-wage workers. Habitat International, 44, 202-210. https://doi.org/10.1016/j. habitatint.2014.06.002

Geurs, K. T., \& Van Wee, B. (2004). Accessibility evaluation of land-use and transport strategies: Review and research directions. Journal of Transport Geography, 12(2), 127-140. https://doi.org/10.1016/j. jtrangeo.2003.10.005

Haddad, M. A. (2020). Residential income segregation and commuting in a Latin American city. Applied Geography, 117, 102186. https://doi.org/10.1016/j.apgeog.2020.102186

Hao, P., Geertman, S., Hooimeijer, P., \& Sliuzas, R. (2012). The land-use diversity in urban villages in Shenzhen. Environment and Planning A, 44(11), 2742-2764. https://doi.org/10.1068/a44696

Hao, P., Geertman, S., Hooimeijer, P., \& Sliuzas, R. (2013). Spatial analyses of the urban village development process in Shenzhen, China. International Journal of Urban and Regional Research, 37(6), 2177-2197. https://doi.org/10.1111/j.1468-2427.2012.01109.x

Hernandez, D. (2018). Uneven mobilities, uneven opportunities: Social distribution of public transport accessibility to jobs and education in Montevideo. Journal of Transport Geography, 67, 119-125.

Hu, L. (2015). Job accessibility of the poor in Los Angeles: Has suburbanization affected spatial mismatch? Journal of the American Planning Association, 81(1), 30-45. https://doi.org/10.1080/019 44363.2015.1042014

Hu, L., Fan, Y., \& Sun, T. (2017). Spatial or socioeconomic inequality? Job accessibility changes for low-and high-education population in Beijing, China. Cities, 66, 23-33.

Huang, J., Levinson, D., Wang, J., \& Jin, H. (2019). Job-worker spatial dynamics in Beijing: Insights from smart card data. Cities, 86, 83-93.

Huang, J., Levinson, D., Wang, J., Zhou, J., \& Wang, Z. J. (2018). Tracking job and housing dynamics with smartcard data. Proceedings of the National Academy of Sciences of the United States of America, 115(50), 12710-12715. https://doi.org/10.1073/pnas.1815928115

Kain, J. F. (1968). Housing segregation, negro employment, and metropolitan decentralization. The Quarterly Journal of Economics, 82(2), 175-197. https://doi.org/10.2307/1885893

Li, L., \& Kleiner, B. H. (2001). The legacy of "danwei" and job performance. Management Research 
News, 24(3/4), 57-66.

Lin, Y., De Meulder, B., Cai, X., Hu, H., \& Lai, Y. (2014). Linking social housing provision for rural migrants with the redevelopment of 'villages in the city': A case study of Beijing. Cities, 40, 111-119. https://doi.org/10.1016/j.cities.2014.03.011

Liu, C.Y., \& Painter, G. (2012). Immigrant settlementand employmentsuburbanization in the US: Is there a spatial mismatch? Urban Studies, 49(5), 979-1002. https://doi.org/10.1177/0042098011405695

Liu, D., \& Kwan, M. P. (2020). Measuring spatial mismatch and job access inequity based on transitbased job accessibility for poor job seekers. Travel Behavior and Society, 19, 184-193. https://doi. org/10.1016/j.tbs.2020.01.005

Liu, T., \& Chai, Y. (2015). Daily life circle reconstruction: A scheme for sustainable development in urban China. Habitat International, 50, 250-260. https://doi.org/10.1016/j.habitatint.2015.08.038

Nanjing Municipal Bureau of Statistics. (2020). Nanjing statistical yearbook 2020 (in Chinese). Nanjing, China: Nanjing Municipal Bureau of Statistics.

Ningbo Municipal Bureau of Statistics. (2020). Ningbo statistical yearbook 2020 (in Chinese). Ningbo, China: Nanjing Municipal Bureau of Statistics.

Qi, Y., Fan, Y., Sun, T., \& Hu, L. (2018). Decade-long changes in spatial mismatch in Beijing, China: Are disadvantaged populations better or worse off? Environment and Planning A: Economy and Space, 50(4), 848-868. https://doi.org/10.1177/0308518X18755747

Shen, Q. (1998). Location characteristics of inner-city neighborhoods and employment accessibility of low-wage workers. Environment and Planning B: Planning and Design, 25(1), 345-365.

Stoll, M. A. (2006). Job sprawl, spatial mismatch, and black employment disadvantage. Journal of Policy Analysis and Management, 25(4), 827-854. https://doi.org/10.1002/pam.20210

Xiamen Municipal Bureau of Statistics. (2020). Xiamen special economic zone yearbook 2020 (in Chinese). Xiamen, China: Xiamen Municipal Bureau of Statistics.

Xiamen Urban Planning and Design Research Institute. (2015). Xiamen household travel survey in 2015 (in Chinese). Xiamen, China: Xiamen Urban Planning and Design Research Institute.

Zhao, P. (2015). The determinants of the commuting burden of low-income workers: Evidence from Beijing. Environment and Planning A, 47(8), 1736-1755. https://doi.org/10.1177/0308518X15597112

Zhao, P., Lü, B., \& De Roo, G. (2011). Impact of the jobs-housing balance on urban commuting in Beijing in the transformation era. Journal of Transport Geography, 19(1), 59-69.

Zhou, S., Liu, Y., \& Kwan, M. P. (2016). Spatial mismatch in post-reform urban China: A case study of a relocated state-owned enterprise in Guangzhou. Habitat International, 58, 1-11. https://doi. org/10.1016/j.habitatint.2016.08.003

Zhou, S., Wu, Z., \& Cheng, L. (2013). The impact of spatial mismatch on residents in Low-income housing neighborhoods: A study of the Guangzhou Metropolis, China. Urban Studies, 50(9), 18171835. https://doi.org/10.1177/0042098012465906

Zhu, P., Zhao, S., Wang, L., \& Yammahi, S. A. (2017). Residential segregation and commuting patterns of migrant workers in China. Transportation Research Part D: Transport and Environment, 52, 586-599. https://doi.org/10.1016/j.trd.2016.11.010 